\title{
The Development of Western Bel Canto
}

\author{
Wang Mengyuan \\ Jiamusi University Jiamusi Heilongjiang 164300
}

Keywords: Western; Bel canto; Development

\begin{abstract}
Bel canto" was originally called Canto in Italy, meaning "beautiful singing". It appeared in Italy in the 17th century and was formed in Europe. It is the most perfect, systematic and scientific singing method in the world. This paper gives a brief account of the history of Bel Canto singing, and explores the germination and birth of Bel Canto singing, the early school of bel canto singing and the development of bel canto singing from the 17th century to the 20th century.
\end{abstract}

\section{Introduction}

There are many kinds of vocal culture in every country in the world, and the bel canto school has become the most scientific school. Bel canto is a kind of singing style originated in Italy in the 17th century. Under the influence of Renaissance trend of thought, opera came into being gradually, and bel canto gradually improved.

\section{The Birth and Birth of Bel canto}

Bel canto originated in Florence, Italy in seventeenth Century. Owing to both subjective and objective conditions, the art of singing has been fully developed in Italy. At that time, Italy had highly trained composers and singers. The Italy language is full of music, such as broad vowels and soft tones. Italians have a strong Lyric temperament and enthusiasm for singing, coupled with their constant practice, exploration and research, so that Italy in the European music world reached an indisputable position. Italian composers and singers know how to create vocal music works and how to make full use of the characteristics of vocal music art to play their charm of vocal music art. Therefore, the reputation of opera in Italy soon spread throughout Europe, and is known as "the land of opera". The Italian singing method lays particular stress on the opera singing method. Language is an important factor to form and create the singing method. They have explored the way of singing - pure vowel singing, which has been appreciated by people all over the world. To some extent, the bel canto singing in Italy outlines the basic principles of developing voice at that time.

\section{Early Bel canto School}

After the birth of Italy opera, German opera, French opera and Russian opera were produced. 


\subsection{P Stoch, Benach and Bologna's Bel canto School}

Born in Bologna, Pistocci showed his musical talent at the age of eight and later joined a juvenile chorus. He performed opera in Ferrara, Vienna and other places, and served as Palma's court singer. And petop's greatest achievement was to become a great singer who sang better than him. In 1705, he said goodbye to the opera stage and established the famous Bologna singing school in his hometown, which was also the first formal vocal music education institution with different grades. He was twice elected chairman of the local philharmonic society. Pistocci is a practitioner of Toshi's teaching principles and methods, and strongly advocates the singing skills with instrumental effects, so his students are well-known in the world of singing, the most outstanding of which is Benazi. The brilliant achievements of teaching made P Stoch a famous vocal educator at that time. For his vocal music teaching, some people have highly appraised its mature and incomparable cultivation and methods, so that students in the shortest time to form a beautiful voice. Benazi is an outstanding baritone opera singer. His voice condition is not very good, but he successfully uses the superb singing skills to cover up his congenital deficiency. His voice was clear and melodious, quick and delicate, with a large number of cheering him as the "king of songs" audience. In particular, in order to avoid the congenital defect of voice, Benazi sings colorful passages without the use of a head or mixed voice, but the use of a full chest. This is a pioneering effort to compete with other singers who do not have such defects. Since 1730, Benache has been teaching singing in Italy. He has inherited the principle of Pistocci's "Bologna School of Singing" and taught the "fast floral singing" invented by him. Singers Senecino, Carlistini and vocal educator Mancini have made remarkable achievements in vocal music education from his studies. Results..

\subsection{Porpora and Ancient Italy's Bel canto Schoo}

Bel canto is not only a method of vocalization or singing, but also a style and genre of singing. It is the embodiment of certain aesthetic principles and artistic ideas. Therefore, the ancient Italian bel canto school, first of all, a school of literary and artistic thought, and then the school of singing. Nicolo Popola was a great vocal educator in the eighteenth century. It is said that some of his operas have pushed the magnificent and difficult skills to extremes and failed to find a singer capable of this kind of singing. There is also a more interesting legend that Popola changed his career to be a "teacher" and wanted to cultivate singers who could sing his difficult songs through his vocal education. Moreover, although the famous Viennese composer Haydn had worshipped under his door, it was obvious that Popola was not famous for it.

\section{The Development of Bel canto in Four,17 and 18 Century}

In the 17th century, this new art form of opera, which was originally performed for aristocratic parties, turned to social performances and became the most popular form of entertainment for the Italian middle class. In order to meet the needs of the audience, many Italian composers began to pursue magnificent scenes and grand scenes. In the second half of the 18th century, Italian operas had a serious tendency to indulge in sound and color effects, while French operas were full of the luxurious and pretentious atmosphere of the Royal aristocracy. After Scarlatti, the freedom of opera creation and performance was brought to the extreme. Opera has degenerated from genuinely dramatic music into endless colorful phrases, trills, ornamental passages and all kinds of colorful treatment, and has become a poor and artistic value of the fancy works. But this abnormal, almost decadent period, also created the singing art is extremely perfect, extremely prosperous "Bel Canto Golden Age". The success of Italian opera in vocal music should be mainly attributed to the castrated singers and vocal music teaching at that time. The Bible's ancient motto states that 
"women should be quiet in church", so Sopranos who sing in the high voice of scriptural songs in churches are deprived of the right to sing. The boy who replaced the soprano became low and thick and lost the flexibility of the female voice. In order to solve this problem, the church began to cultivate castrated singers consciously from the end of sixteenth Century. From the 1840s, especially in the 18th century, castrated singers not only excluded female voices, but also, to a certain extent, male voices. Despite the outstanding achievements of the castrated singers in their singing skills, this is an inhumane historical phenomenon. As a result, the castrated singer began to decline in the late eighteenth Century, leaving almost nothing in nineteenth Century.

\section{The Development of Bel Canto in 19 Century}

In the early 19th century, Italian Bel Canto Opera composer Rossini began to write colorful passages into fixed scores, resisting the atmosphere of arbitrary floral addition. However, this kind of residual wind has been maintained until the early 20th century, people call this kind of singing style with arbitrary floral or decorative singing. From the early 18th century to the middle of the 19th century, a style of singing in Italy was prevalent, which was rich in beauty, elasticity, recitation or dramatic effect. "Bel Canto" was formed in the middle of the nineteenth Century as a musical term. Rossini said: "A bel canto singer should have three conditions: first, a natural and beautiful voice, each of its entire vocal range should be uniform; second, through careful training, in singing high-pitched and ostentatious passages without any effort; third, mastering the kind of Italian singing that only by listening to the best of all. The style that we can learn. Bel canto singing art, as the superstructure reflecting the economic foundation, is the portrayal and record of life. In the years of opera left a large number of perfect opera works, which contains about singing techniques.

\section{The Development of Bel Canto in 20 Century}

After a period of decline in nineteenth Century, bel canto has ushered in the revival and prosperity in twentieth Century.

\subsection{Resurgence of Bel Canto}

Caruso, an Italian tenor, is known as the "king" and "greatest tenor of all time" and "greatest singer of the millennium". Caruso's voice was strong, loud and warm, and at the same time it was soft, clear and sweet. His breathing control and clausal method are very perfect, and his long phrases can be sung with ease. He naturally melted the beauty of voice into his thoughts and feelings, and emphasized the expression of emotion and meaning in lyrics. In 1902, Caruso and the world famous soprano Melba joined the stage to sing the Italian opera composer Puccini's masterpiece "The Artist's Career", ushered in the revival of the 20th century Bel canto. Caruso has performed more than 50 operas in his life and has played nearly 70 different tenor operas. In terms of both vocal technique and performance effect, he has reached the highest level ever in tenor field. Carlas was the first singer to recover his bel canto skills after the decline of Bel canto. She is also a singer who really combines dramatic intensity with flowery singing. She almost sang all the important characters in the opera with her voice of change.

\subsection{Three Tenors}

Pavarotti is a famous tenor in Italy and is known as "king of high pitched C". Pavarotti inherited and developed the Italian tenor since Caruso, and sang nine powerful tenor C's using head and chest resonances. He has the world's first-rate beautiful voice, and his voice is natural, fluent and full of 
personality. In his broad range, all the sounds can be pronounced freely, even the strong and powerful tenor is also mellow, beautiful, clear. Domingo, a Spanish tenor, is one of the outstanding tenors in contemporary times. He is called "the king of opera" because he has created numerous moving artistic images on the opera stage. Domingo has a dark tone, in the dark and sweet, its stage performance is beautiful, natural, accurate and delicate, singing with tragic tenor role is very appealing. Domingo's voice is very suitable for singing dramatic tension of the role, has been recognized as Verdi, Puccini works of excellent interpreters. Domingo's repertoire is far more than all tenors since Caruso. Carreras, Spanish tenor, one of the most influential western singers in the late twentieth Century. His voice is smooth and sweet, the breath is even, the line is clear, the singing field is broad, is a handsome, soft voice characteristics of Lyric tenor. Carreras'singing performance combines simplicity and innocence, pays attention to voice and expression, carefully adjusts the balance between singing skills and drama performance. Besides singing operas, Italian, French and Western operas, he also involves modern musicals

\subsection{Other Famous Singers}

Chaliapin is a Russian bass singer and one of the leading figures in world vocal vocalists. He sang a large number of Russian folk songs and classical art songs, and introduced Russian opera art and folk songs to the Western cultural life, and made outstanding contributions to the development of Russian vocal music. Chariabin can sing both bass and baritone, his voice is loud and powerful, wide range, changeable and flexible timbre, and sound free, perfect, good at performing, can portray the character's personality, psychology and spiritual temperament vividly. Shariabin is not only an outstanding representative in the history of Russian vocal music, but also the first worldclass vocal master to sing in China. Geely is a tenor in Italy and is recognized as the tenor of the world. After his death in Caruso, Geely undertook the burden of the continued development of Bel canto. He abided by the supreme principle of Bel canto and grasped his singing strictly according to its scale, which laid the foundation for contemporary Bel canto. Geely sang more than 60 operas, a large number of religious songs and European and American folk songs, and left a large number of vocal heritage, including 15 audio films and 8 recorded operas on slow-motion records. His singing involves various types of tenors, but Lyric tenor is the main form.

\section{Conclusions}

The vocal music stage in twentieth Century can be seen as a hundred flowers and a variety of singing styles and schools coexist. The competition of these schools has brought about a variety of singing methods, and it is also a manifestation of the increasingly scientific and perfect Bel canto.

\section{References}

[1] Yang Yonggang. On the influence of Bel Canto on the national vocal music teaching in China [J]. music time and space, 2015 (24).

[2] Liu Lei. The artistic and emotional analysis of bel canto. [J]. Drama House, 2015 (23).

[3] Wang Jing, Hu Yifang. The shaping of singing instruments should follow the law of development [J].Journal of Hubei Institute of Science and Technology, 2015 (09).

[4] Liu Jinli Bel Canto and national singing. [J]. music time and space, 2015 (24). 